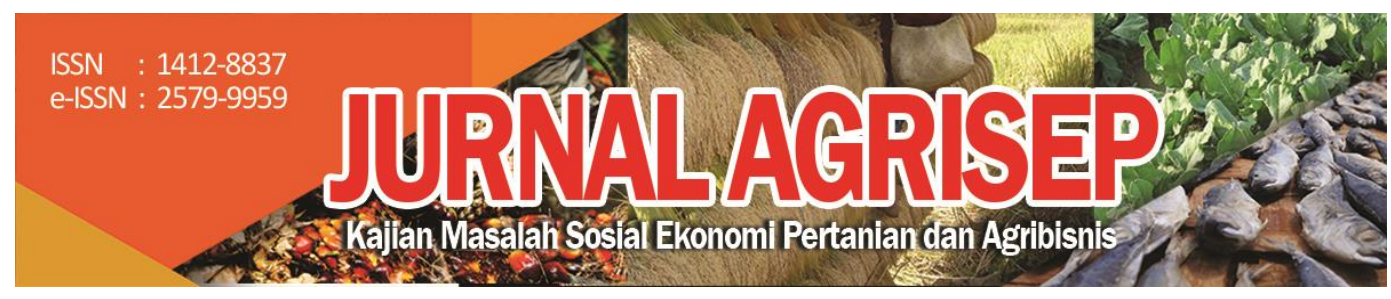

DOI: 10.31186/jagrisep.19.1.43-52

\title{
PENGARUH DANA DESA TERHADAP DISPARITAS PEMBANGUNAN ANTAR KABUPATEN DI PROVINSI BENGKULU
}

\section{The Influence Of Village Funds On Development Disparity Between Districts In Bengkulu Province}

\author{
Wazir Hutapia $\left.{ }^{1}\right)^{\otimes}$ dan Benardin Almanuar ${ }^{2)}$ \\ ${ }^{1,2)}$ Department of Development Economics, Faculty of Economics and Business, \\ Bengkulu University, Indonesia \\ Email: hutapia_bengkulu@yahoo.co.id
}

\begin{abstract}
The problem of development disparity between districts and cities in Bengkulu Province, as indicated by the relatively high and fluctuating Gini Index figures, meanwhile village funds received by the district government always increase from year to year. Therefore this study aims to find out how much influence village funds have on development disparities between districts in Bengkulu province. This study uses secondary data, obtained from the Central Statistics Bureau and the Ministry of Finance. The research sample was all districts in Bengkulu Province, except Bengkulu City because they did not receive village fund, and analysis techniques using the Panel Data regression model. The appropriate model is Fixed Effect, but the regression coefficient is very small but it has a role in reducing development inequality (Gini Index). The small effect is because the village fund provided are still very small and the formulation of the distribution of village funds is not pro to the poor population. Many other factors affect development inequality such as: differences in endowment factors, demographic conditions, lack of smooth mobility of goods and services, concentration of regional economic activities, allocation of development funds between regions.
\end{abstract}

Keywords: fund village, development disparity

\section{ABSTRAK}

Ketimpangan pembangunan antara kabupaten dan kota di Provinsi Bengkulu seperti ditunjukkan oleh angka Indeks Gini yang relatif tinggi dan berfluktuasi, sementara itu dana desa yang diterima oleh pemerintah kabupaten di provinsi Bengkulu selalu meningkat dari tahun ke tahun. Oleh karena itu penelitian ini 
bertujuan untuk mengetahui seberapa besar pengaruh dana desa terhadap ketimpangan pembangunan antar kabupaten di provinsi Bengkulu. Penelitian ini menggunakan data sekunder yang diperoleh dari Badan Pusat Statistik (BPS) dan Kementerian Keuangan. Sampel penelitian adalah seluruh kabupaten di Provinsi Bengkulu, kecuali kota Bengkulu karena tidak mendapat bantuan dana desa, dan teknik analisis menggunakan model regresi Data Panel. Hasil penelitian menemukan bahwa Fixed Effect adalah model terbaik. Meskipun koefisien regresinya sangat kecil, dana desa berperan dalam mengurangi ketimpangan pembangunan (Indeks Gini). Kecilnya pengaruh tersebut dikarenakan dana desa yang diberikan masih sangat kecil dan formulasi distribusi dana desa tidak pro kepada penduduk miskin. Banyak faktor lain yang mempengaruhi ketimpangan pembangunan seperti: perbedaan faktor anugrah awal (endowment factor), perbedaan kondisi demografis, kurang lancarnya mobilitas barang dan jasa, konsentrasi kegiatan ekonomi wilayah, alokasi dana pembangunan antar wilayah.

Kata Kunci: Dana Desa, Ketimpangan Pembangunan

\section{PENDAHULUAN}

Setiap tahun Pemerintah Pusat telah menganggarkan dana desa yang cukup besar untuk diberikan kepada Desa, pada tahun 2015 dana desa dianggarkan sebesar Rp20,7 triliun, dengan rata-rata tiap desa mendapatkan alokasi sebesar Rp280 juta (Kemenkeu RI, 2017), dan pada tahun 2018 dana desa dianggarkan sebesar Rp.60 Triliun dengan tingkat serapan anggaran mencapai 99,03 persen (Kemendes PDTT, 2014). Untuk provinsi Bengkulu, besarnya bantuan dana desa yang diterima tahun anggaran 2015 untuk 9 (sembilan) kabupaten sebesar Rp. 362.962.239.000,-. Besaran dana desa yang diterima masing-masing kabupaten tidak sama, sesuai dengan banyaknya desa di masing-masing kabupaten, adapun kabupaten yang mendapat dana desa paling besar adalah kabupaten Bengkulu Utara sebesar Rp. 58.318.640.000,-, sedangkan kabupaten yang mendapat dana desa paling kecil adalah kabupaten Lebong, yaitu sebesar Rp. 25.447.255.000. Selanjutnya pada tahun 2017 dana desa yang diterima meningkat menjadi lebih dari satu trilyun, yaitu sebesar Rp 1.035.340.413.000, namun pada tahun 2018 dana desa yang diterima menurun menjadi Rp.946.393.453.000.

Seperti diketahui bahwa dana desa yang dialokasikan pemerintah bertujuan antara lain untuk mendukung meningkatnya kesejahteraan masyarakat, mengurangi kemiskinan serta pemerataan pembangunan dan mengentaskan ketimpangan daerah tertinggal dengan harapan agar daerah desa tersebut menjadi maju. Berdasarkan laporan Indeks Pembangunan Desa (IPD) di Provinsi Bengkulu secara rata-rata masih dibawah nasional dan berada pada urutan terendah kedua di pulau Sumatera (BPS, 2019). Data ini secara implisit menunjukkan bahwa pembangunan desa di provinsi Bengkulu belum mengalami kemajuan yang signifikan dibandingkan dengan daerah lainnya. 
Dilihat dari data angka indeks Gini di provinsi Bengkulu, menunjukkan tingkat ketimpangan pembangunan dalam lima tahun terakhir (tahun 2014 2018) tidak mengalami perubahan yang signifikan, data yang ada menunjukkan terjadi fluktuasi dari tahun ke tahun dan cenderung berada pada kategori ketimpangan sedang. Angka indeks Gini provinsi Bengkulu tahun 2014 tercatat sebesar 0,36, selanjutnya terjadi kenaikan pada tahun 2015 menjadi 0,37, namun pada tahun 2016 menurun menjadi 0,35 dan pada tahun 2017 angka indeks Gini tetap tidak berubah sebesar 0,35, tetapi pada tahun 2018 angka ini bukannya mengalami penurunan, justru meningkat lagi menjadi 0,36 (BPS, 2019).

Mencermati angka Indeks Pembangunan Desa (IPD) di Provinsi Bengkulu yang secara rata-rata masih lebih rendah dibandingkan angka ratarata IPD secara nasional dan angka indeks Gini provinsi Bengkulu yang relative tinggi (berada pada kategori ketimpangan sedang) menunjukkan pembangunan desa di Provinsi Bengkulu belum mengalami kamajuan yang signifikan dan distribusi pendapatan antar kelompok dalam masyarakat masih relatif kurang merata.

Berdasarkan uraian diatas mengindikasikan terjadinya ketimpangan pembangunan antar kabupaten dan kota di Provinsi Bengkulu yang ditunjukkan oleh angka Indeks Gini yang relatif tinggi dan berfluktuasi, sementara itu dana desa yang diterima oleh pemerintah kabupaten di provinsi Bengkulu selalu meningkat dari tahun ke tahun, oleh karena itu penelitian ini bertujuan untuk mengetahui bagaimana pengaruh dana desa terhadap ketimpangan pembangunan antar kabupaten di provinsi Bengkulu.

\section{METODE PENELITIAN}

Jenis penelitian ini adalah menggunakan metode deskriptif kuantitatif. Data yang digunakan adalah data sekunder dari 9 (Sembilan) kabupaten di Provinsi Bengkulu, yaitu data Gini rasio dan Dana Desa selama tahun 2015 2018 yang diperoleh dari Badan Pusat Statistik (BPS), Kementerian Keuangan dan instansi terkait lainnya.

\section{HASIL DAN PEMBAHASAN}

\section{Perkembangan Dana Desa Yang diterima Pemerintah Kabupaten di Provinsi Bengkulu}

Sejak tahun 2015 pemerintah pusat memberikan bantuan dana desa kepada pemerintah provinsi Bengkulu untuk 9 (sembilan) kabupaten tidak termasuk kota Bengkulu. Secara rinci besaran dana desa yang diterima masingmasing pemerintah kabupaten di Provinsi Bengkulu dari tahun 2015-2018 dapat dilihat pada tabel 1 berikut. 
Tabel 1. Dana Desa yang diterima Pemerintah Kabupaten di Provinsi Bengkulu, Tahun 2015-2018 (ribu rupiah)

\begin{tabular}{clrrrr}
\hline No & Kabupaten & $\mathbf{2 0 1 5}$ & \multicolumn{1}{c}{$\mathbf{2 0 1 6}$} & \multicolumn{1}{c}{$\mathbf{2 0 1 7}$} & \multicolumn{1}{c}{$\mathbf{2 0 1 8}$} \\
\hline 1 & Bengkulu Selatan & 38.790 .715 & 87.029 .059 & 110.746 .649 & 97.393 .929 \\
2 & Bengkulu Utara & 58.318 .640 & 130.594 .550 & 166.310 .259 & 146.743 .965 \\
3 & Rejang Lebong & 33.338 .960 & 74.796 .332 & 95.495 .934 & 97.025 .890 \\
4 & Kaur & 51.138 .239 & 114.705 .102 & 145.777 .851 & 129.967 .425 \\
5 & Seluma & 48.899 .525 & 109.690 .905 & 139.486 .234 & 126.493 .638 \\
6 & Mukomuko & 40.360 .009 & 90.529 .932 & 115.058 .353 & 106.523 .093 \\
7 & Lebong & 25.447 .255 & 56.982 .592 & 72.563 .476 & 68.334 .766 \\
8 & Kepahiang & 28.660 .854 & 64.305 .935 & 81.496 .596 & 74.958 .035 \\
9 & Bengkulu Tengah & 38.008 .042 & 85.262 .139 & 108.405 .061 & 98.197 .538 \\
\hline & Jumlah & 362.962 .239 & 813.896 .546 & 1.035 .340 .413 & 945.638 .279 \\
\hline
\end{tabular}

Sumber: Kemenkeu RI, beberapa tahun

Apabila jumlah dana desa yang diterima pemerintah masing-masing Kabupaten di Provinsi Bengkulu dikaitkan dengan banyaknya jumlah desa masing-masing Kabupaten, menunjukkan bahwa besaran dana desa yang diterima hampir relative sama nilainya dan tidak terdapat variasi ketimpangan yang cukup mencolok, seperti dapat dilihat pada tabel 2 berikut.

Tabel 2. Dana Desa yang diterima Pemerintah Kabupaten di Provinsi Bengkulu, Tahun 2015-2018 menurut jumlah Desa (rupiah)

\begin{tabular}{lcccc}
\hline \multicolumn{1}{c}{ Kabupaten } & $\mathbf{2 0 1 5}$ & $\mathbf{2 0 1 6}$ & $\mathbf{2 0 1 7}$ & $\mathbf{2 0 1 8}$ \\
\hline Bengkulu Selatan & 273.174 .049 & 612.880 .697 & 779.905 .979 & 685.872 .739 \\
Bengkulu Utara & 271.249 .488 & 607.416 .512 & 773.536 .088 & 682.530 .070 \\
Rejang Lebong & 273.270 .164 & 613.084 .689 & 782.753 .557 & 795.294 .180 \\
Kaur & 266.344 .995 & 597.422 .406 & 759.259 .641 & 676.913 .672 \\
Seluma & 268.678 .709 & 602.697 .280 & 766.407 .879 & 695.019 .989 \\
Mukomuko & 272.702 .764 & 611.688 .730 & 777.421 .304 & 719.750 .628 \\
Lebong & 273.626 .398 & 612.716 .043 & 780.252 .430 & 734.782 .430 \\
Kepahiang & 272.960 .514 & 612.437 .476 & 776.158 .057 & 713.886 .048 \\
Bengkulu Tengah & 267.662 .268 & 600.437 .599 & 763.415 .923 & 691.531 .958 \\
\hline Prov. Bengkulu & 271.074 .372 & 607.864 .603 & 773.234 .540 & 710.620 .190 \\
\hline
\end{tabular}

Sumber: Data diolah, 2019

Jika jumlah dana desa yang diterima pemerintah masing-masing Kabupaten di Provinsi Bengkulu dibagi dengan banyaknya jumlah penduduk miskin masing-masing Kabupaten, menunjukkan bahwa terdapat variasi ketimpangan yang cukup mencolok dalam pembagian dana desa per kapita penduduk miskin masing-masing kabupaten, seperti dapat dilihat pada tabel 3 berikut. 
Tabel 3. Dana Desa per penduduk miskin masing-masing Pemerintah Kabupaten di Provinsi Bengkulu, 2015-2018 (Rupiah)

\begin{tabular}{lrlrr}
\hline \multicolumn{1}{c}{ Kabupaten } & $\mathbf{2 0 1 5}$ & $\mathbf{2 0 1 6}$ & $\mathbf{2 0 1 7}$ & \multicolumn{1}{c}{$\mathbf{2 0 1 8}$} \\
\hline Bengkulu Selatan & 1.124 .043 & 2.565 .715 & 3.390 .896 & 3.336 .551 \\
Bengkulu Utara & 1.380 .650 & 3.276 .331 & 4.267 .648 & 4.101 .285 \\
Rejang Lebong & 724.130 & 1.633 .464 & 2.177 .786 & 2.303 .012 \\
Kaur & 1.939 .258 & 4.388 .106 & 5.723 .512 & 5.602 .044 \\
Seluma & 1.151 .390 & 2.702 .412 & 3.554 .695 & 3.372 .264 \\
Mukomuko & 1.705 .112 & 3.860 .551 & 5.111 .433 & 4.954 .562 \\
Lebong & 1.901 .888 & 4.202 .256 & 5.451 .801 & 5.157 .341 \\
Kepahiang & 1.291 .611 & 2.956 .595 & 3.795 .836 & 3.828 .296 \\
Bengkulu Tengah & 4.256 .220 & 8.974 .962 & 11.631 .444 & 10.627 .439 \\
\hline \multicolumn{1}{c}{ Rata-rata } & 1.719 .367 & 3.840 .044 & 5.011 .672 & 4.809 .199 \\
\hline
\end{tabular}

Sumber: Data diolah, 2019

Berdasarkan tabel 3, kabupaten Rejang Lebong menerima dana desa paling kecil, misalnya pada tahun 2018 mendapat bantuan dana desa sebesar Rp. 2.303.012 per penduduk miskin, sedangkan kabupaten Bengkulu Tengah menerima kucuran dana desa sebesar Rp. 10.627.439 per penduduk miskin, nilai ini hampir mencapai 5 (lima) kali lipat. Hal ini dikarenakan formula pembagian dana desa tidak pro pada jumlah penduduk miskin.

\section{Ketimpangan Pembangunan}

Angka indeks Gini provinsi Bengkulu dalam lima tahun terakhir menunjukkan berfluktuasi dan cenderung berada pada kategori ketimpangan sedang, begitu juga jika dilihat pada tingkat kabupaten/kota (lihat Tabel 4).

Tabel 4. Gini Ratio Pemerintah Kabupaten/Kota di Provinsi Bengkulu, Tahun 2014 - 2018

\begin{tabular}{lccccc}
\hline \multicolumn{1}{c}{ Wilayah } & \multicolumn{5}{c}{ Gini Ratio Kabupaten/Kota } \\
& $\mathbf{2 0 1 4}$ & $\mathbf{2 0 1 5}$ & $\mathbf{2 0 1 6}$ & $\mathbf{2 0 1 7}$ & $\mathbf{2 0 1 8}$ \\
\hline Bengkulu Selatan & 0.4 & 0.39 & 0.34 & 0.37 & 0.36 \\
Rejang Lebong & 0.31 & 0.33 & 0.36 & 0.32 & 0.33 \\
Bengkulu Utara & 0.31 & 0.35 & 0.31 & 0.31 & 0.35 \\
Kaur & 0.37 & 0.38 & 0.33 & 0.32 & 0.31 \\
Seluma & 0.29 & 0.35 & 0.32 & 0.33 & 0.31 \\
Mukomuko & 0.34 & 0.32 & 0.3 & 0.31 & 0.32 \\
Lebong & 0.31 & 0.32 & 0.27 & 0.3 & 0.29 \\
Kepahiang & 0.3 & 0.34 & 0.3 & 0.33 & 0.30 \\
Bengkulu Tengah & 0.35 & 0.37 & 0.3 & 0.28 & 0.29 \\
Kota Bengkulu & 0.35 & 0.4 & 0.37 & 0.37 & 0.39 \\
\hline
\end{tabular}

Sumber: BPS Provinsi Bengkulu, 2019 
Mencermati perkembangan angka indeks Gini pemerintah antar Kabupaten/kota di provinsi Bengkulu menunjukkan penurunan yang cukup lambat, seperti yang tersaji pada Tabel 4, hanya kabupaten Kaur dan Bengkulu Tengah yang berhasil dengan cepat menurunkan angka ketimpangan. Sementara itu terdapat perbedaan yang cukup signifikan angka ketimpangan antar pemerintah kabupaten dan kota, dengan rentang antara 0,29 - 0,39.

\section{Estimasi Model Regresi Data Panel}

\section{Pemilihan Model Terbaik}

Untuk mengetahui model terbaik yang mana yang akan dipilih, maka dilakukan terlebih dahulu uji Chow dan uji Hausman.

\section{Uji Chow}

Uji Chow dilakukan untuk memilih mana yang terbaik antara Common Effect Model atau Fixed Effect Model. Dari hasil uji Chow diperoleh nilai probabilitas cross-section $F$ adalah sebesar 0,0002. Probabilitas ini lebih kecil dari pada alpha $(\mathrm{a}=0,05)$. Hal ini menunjukkan bahwa $\mathrm{H}_{0}$ : common effect model ditolak dan $\mathrm{H}_{1}$ : fixed effect model diterima, sehingga model fixed effect lebih tepat dibandingkan dengan model common effect.

\section{Uji Hausman}

Uji Hausman dilakukan untuk memilih mana yang terbaik antara metode antara Random Effect dengan Fixed Effect. Jika Ho diterima maka model yang terbaik digunakan adalah model Random Effect. Dari uji Hausman diperoleh nilai Prob cross-section random $=0.0153$ lebih kecil dari 0.05, menunjukkan kondisi ditolaknya $\mathrm{H}_{\mathrm{O}}$, maka dengan tingkat keyakinan 95\% model fixed effect lebih sesuai digunakan.

\section{Hasil Analisis Regresi Linear Berganda}

\section{Persamaan regresi}

Dari hasil pengolahan data dan estimasi, dapat dibuat persamaan regresi data panel model fixed effect pengaruh dana desa terhadap ketimpangan pembangunan antar kabupaten di provinsi Bengkulu, sebagai berikut: $\mathrm{Y}=0,3646-0.000449 \mathrm{X}$

Dari hasil persamaan regresi tersebut dapat dikatakan bahwa ada pengaruh negatif antara jumlah dana desa dengan tingkat ketimpangan pembangunan (Indeks Gini), artinya jika jumlah dana desa bertambah atau meningkat maka mengakibatkan tingkat ketimpangan pembangunan akan menurun. Selanjutnya jika variabel-variabel independen lain dianggap konstan 
atau bernilai nol (tidak mengalami peningkatan atau penurunan), maka besarnya Indeks Gini adalah sebesar 0,364626.

Pada model estimasi persamaan regresi untuk masing-masing kabupaten di provinsi Bengkulu, terlihat bahwa adanya pengaruh cross-section yang ada di setiap kabupaten terhadap ketimpangan pembangunan (Indeks Gini) antar kabupaten di provinsi Bengkulu. Kabupaten yang memiliki pengaruh cross-section yang bernilai positif paling tinggi adalah Kabupaten Bengkulu Selatan dan kabupaten Bengkulu Utara. Selanjutnya kabupaten yang memiliki pengaruh cross-section yang bernilai negatif paling besar adalah Kabupaten Lebong. Jika diasumsikan dana desa tidak ada maka kedua kabupaten (Kabupaten Bengkulu Selatan dan kabupaten Bengkulu Utara) tersebut memiliki tingkat ketimpangan (Indeks Gini) yang paling tinggi dan kabupaten Lebong memiliki tingkat ketimpangan (Indeks Gini) yang paling rendah.

\section{Uji Hipotesis}

\section{Uji Hipotesis Parsial (Uji t)}

Dari hasil perhitungan $\mathrm{t}$ statistik, diperoleh nilai t-Statistic sebesar 4.259397, dengan prob.0,0002, maka dapat disimpulkan terdapat pengaruh yang signifikan dan negatif dari dana desa terhadap tingkat ketimpangan pembangunan antar kabupaten di provinsi Bengkulu.

\section{Uji Koefisien Determinasi $\left(R^{2}\right)$}

Hasil perhitungan analisis regresi diperoleh nilai Adj $R^{2}$ sebesar 0.564715, yang menunjukkan bahwa kontribusi variabel dana desa dalam menjelaskan variasi terhadap tingkat ketimpangan pembangunan sebesar $56,47 \%$, sedangkan $43,53 \%$ dijelaskan oleh variabel lain yang tidak dimasukkan dalam model penelitian. Ini berarti bahwa banyak faktor lainnya yang mempengaruhi ketimpangan pembangunan seperti: perbedaan faktor anugrah awal (endowment factor), kondisi demografis, kurang lancarnya mobilitas barang dan jasa, konsentrasi kegiatan ekonomi wilayah, alokasi dana pembangunan antar wilayah (Syafrizal (2008), Kuncoro (2006), Sukirno (2010).

\section{PEMBAHASAN}

\section{Pengaruh Dana Desa terhadap Ketimpangan Pembangunan}

Dari hasil uji hipotesis menunjukkan bahwa variabel dana desa yang diterima pemerintah kabupaten di Provinsi Bengkulu berpengaruh negatif dan signifikan terhadap ketimpangan pembangunan (Indeks Gini). Jika besaran dana desa mengalami peningkatan sebesar 1 milyar rupiah yang diterima 
pemerintah kabupaten di Provinsi Bengkulu, maka angka Gini rasio akan mengalami penurunan sebesar 0,000449 dan sebaliknya. Hasil ini sesuai dengan hipotesis bahwa terdapat pengaruh yang signifikan dari dana desa dalam mengurangi ketimpangan pembangunan (Indeks Gini). Dilihat dari besaran koefisien regresi hanya sebesar 0,000449 menunjukkan bahwa pengaruh dana desa dalam mengurangi ketimpangan pembangunan tidaklah begitu besar pengaruhnya. Hal ini disebabkan besaran dana desa yang disalurkan pemerintah masih sangat kecil, terlebih pada tahap awal penyalurannya di provinsi Bengkulu pada tahun 2015 rata-rata setiap desa hanya menerima dana desa sebesar Rp.271 juta.

Berdasarkan hasil penelitian ditemukan bahwa dana desa yang diterima antar pemerintah kabupaten di Provinsi Bengkulu, sangat bervariasi dan besarnya bantuan dana desa tidak proporsional dengan banyaknya jumlah penduduk miskin masing-masing kabupaten, tetapi pola pembagian distribusi besaran nominal dana desa dari pemerintah pusat kepada pemerintah kabupaten di Provinsi Bengkulu lebih banyak didasarkan pada jumlah desa, dengan kata lain besarnya bantuan dana desa didasarkan konsep pemerataan antar desa.

Hasil penelitian ini sejalan dengan tujuan pemerintah menyalurkan dana desa yaitu agar dapat meningkatnya kesejahteraan masyarakat dan mengentaskan kemiskinan serta pemerataan pembangunan dan mengurangi ketimpangan pembangunan, dimana Dana Desa telah berhasil menurunkan rasio ketimpangan perdesaan dari 0,34 pada tahun 2014 menjadi 0,32 di tahun 2017 (Kemenkeu, 2017). Lebih lanjut, temuan hasil penelitian ini hampir sejalan dengan penelitian Aghnia, (2018), dimana dana desa signifikan berpengaruh positif terhadap pengentasan kemiskinan di Indonesia. Begitu juga Susilowati dkk, (2017) menganalisis pengaruh alokasi dana desa, dana desa, belanja modal, dan produk domestik regional bruto terhadap kemiskinan Kabupaten/Kota di Provinsi Jawa Timur, dengan menggunakan regresi dengan data panel, menunjukkan bahwa variabel alokasi dana desa, dana desa, belanja modal, dan produk domestik regional bruto berpengaruh terhadap kemiskinan Kabupaten / Kota. Sementara itu hasil penelitian Lalira, Dianti, dkk (2018), mengenai pengaruh dana desa dan alokasi dana desa terhadap tingkat kemiskinan, tidak berpengaruh signifikan terhadap tingkat kemiskinan di kecamatan Gemeh Kabupaten Kepulauan Talaud. Sedangkan Jamaluddin, Yanhar dkk (2018), menganalisis dampak pengelolaan dan penggunaan dana desa terhadap pembangunan daerah, dengan menggunakan pendekatan kualitatif, hasil analisis menunjukkan bahwa pengelolaan dan penggunaan Dana Desa tidak memberi dampak signifikan bagi pertumbuhan pembangunan daerah dan program pembangunan Desa tidak sinkron dengan kebijakan pembangunan Daerah (RPJM Daerah). 
Berdasarkan hasil penelitian ditemukan bahwa dana desa yang diterima antar pemerintah kabupaten di Provinsi Bengkulu, sangat bervariasi dan besarnya bantuan dana desa tidak proporsional dengan banyaknya jumlah penduduk miskin masing-masing kabupaten, tetapi pola pembagian distribusi besaran nominal dana desa dari pemerintah pusat kepada pemerintah kabupaten di Provinsi Bengkulu lebih banyak didasarkan pada jumlah desa, dengan kata lain besarnya bantuan dana desa didasarkan pada konsep pemerataan antar desa.

Formula pembagian Dana Desa dilakukan saat ini adalah 90 persen dana desa dibagi rata sebagai alokasi dasar dan 10 persen dibagi berdasarkan empat variabel (jumlah penduduk desa 25\%, angka kemiskinan desa 35\%, luas wilayah desa $10 \%$, dan tingkat kesulitan geografis desa 30\%). Formula tersebut perlu ditinjau ulang dengan memberi bobot (penimbang) yang lebih besar pada aspek kemiskinan dan ketimpangan pembangunan. Formula dana desa dapat berkontribusi pada peningkatan ketimpangan, mengingat keberagaman desa yang sangat besar antardaerah, bahkan di dalam suatu wilayah/provinsi, sebesar 65 persen dan 35 persen (KOMPAK,2017).

\section{SIMPULAN DAN SARAN}

\section{Simpulan}

1. Variabel dana desa berpengaruh dalam menurunkan ketimpangan pembangunan (Indeks Gini) pemerintah kabupaten di Provinsi Bengkulu.

2. Kontribusi variabel dana desa dalam menjelaskan variasi terhadap tingkat ketimpangan pembangunan hanya sebesar 56,57\%, sedangkan $43,43 \%$ dijelaskan oleh variabel lain yang tidak dimasukkan dalam model penelitian.

\section{Saran}

Beberapa saran yang dapat diberikan, yaitu :

1. Untuk mendapatkan gambaran yang lebih komprehensif terhadap ketimpangan pembangunan dan dana desa perlu dilakukan penelitian lanjutan dengan menggunakan variabel lain yang lebih komprehensip dan model lainnya sebagai bahan pembanding.

2. Memperbaiki dan mereformulasi pola alokasi dan distribusi dana desa dengan memperhatikan aspek kemiskinan dan ketimpangan pembangunan. Pembagian dana desa dilakukan berdasarkan alokasi dasar sebesar 90 persen dan 10 persen sisanya masuk dalam alokasi formula perlu dilakukan perbaikan agar efektivitas penurunan ketimpangan pembangunan lebih optimal. 


\section{DAFTAR PUSTAKA}

Aghnia, Nadya Larasati. 2018. Pengaruh Dana Desa dalam Pengentasan Kemiskinan di Indonesia, Departemen Ilmu Ekonomi Fakultas Ekonomi Dan Manajemen Institut Pertanian Bogor (Skripsi tidak di publikasikan).

Badan Pusat Statistik. 2019. Indeks Pembangunan Desa 2018. Jakarta: BPS

Badan Pusat Statistik. 2019. Gini Rasio Kabupaten / Kota di Provinsi Bengkulu. Bengkulu: BPS

Bengkulu Ekspress. 2018. Dana Desa Tingkatkan Kesejahteraan Masyarakat. Bengkulu: Bengkulu Ekspress

Jamaluddin, Yanhar dkk. 2018. Dampak pengelolaan dan penggunaan Dana Desa terhadap pembangunan daerah. Jurnal Ilmu Pemerintahan dan Sosial Politik UMA, 6(1): 14-24.

KOMPAK. 2017. Dana Desa dan Penanggulangan Kemiskinan, Kemitraan Pemerintah Australia-Indonesia dikelola oleh Abt Associates, Kementerian PPN/Bappenas dan Australian Government

Kuncoro, Mudrajad. 2010. Dasar- dasar Ekonomika Pembangunan. Yogyakarta: UPP STIM YKPN Yogyakarta.

Lalira, Dianti, dkk (2018), Pengaruh Dana Desa Dan Alokasi Dana Desa Terhadap Tingkat Kemiskinan Di Kecamatan Gemeh Kabupaten Kepulauan Talaud. Jurnal Berkala Ilmiah Efisiensi. 18(4): 62-72.

Kemendes. 2014. Undang Undang Nomor 6 Tahun 2014 tentang Desa

Republik Indonesia. 2015. Peraturan Presiden RI nomor 36 tahun 2015 Tentang Rincian APBN Tahun Anggaran 2015, Lampiran XXII tentang rincian dana desa menurut Kabupaten/Kota.

Republik Indonesia. 2016. Peraturan Pemerintah Nomor Nomor 8 Tahun 2016 tentang Dana Desa yang bersumber dari APBN.

Kemenkeu RI. 2018. Buku Saku Dana Desa. Jakarta: Kementerian Keuangan.

Republik Indonesia, (2018) Peraturan Menteri Keuangan, nomor 226/PMK.07/2017 Perubahan Rincian Dana Desa menurut daerah Kabupaten/Kota Tahun Anggaran 2018, Kementerian Keuangan.

Sjafrizal, 2008. Ekonomi Regional: Teori dan Aplikasi. Padang: Baduose Media.

Susilowati, N.I., Susilowati, D., Hadi, S. 2017 Pengaruh Alokasi Dana Desa, Dana Desa, Belanja Modal, dan Produk Domestik Regional Bruto terhadap kemiskinan Kabupaten/Kota di Provinsi Jawa Timur. Jurnal Ilmu Ekonomi. 1(4): 514-526

52 | Hutapia; Benardin; Pengaruh Dana Desa Terhadap Disparitas...... 